\title{
Left Radial versus Femoral Coronary Angiography in Post CABG Patients
}

\author{
MOHAMED MAKRAM, M.D.* and TAMER EL BANNA, M.D.** \\ The Departments of Cardiology* and Cardiothoracic Surgery**, National Heart Institute
}

\begin{abstract}
Background: Coronary angiography via TRA approach (TRA) has gained growing acceptance and operator preference in recent years, based on a reduction in vascular complications and mortality.

Aim of Study: This study was aimed to Compare left radial versus femoral artery approach during coronary angiography in patients post CABG especially in fluoroscopy time and contrast amount.

Patients and Methods: Our study was a single center, retrospective cohort study was done on 100 patients to compare procedural variables especially fluoroscopy time and contrast amount of TRA versus TFA catheterization in patients who had previously undergone CABG surgery. In the period between February 2020 and February 2021, 100 patients who had previously undergone CABG surgery and had received diagnostic or interventional cardiac catheterizations at our institute were included in the study population.
\end{abstract}

Results: Our results observed in Table (1) cleared that, the number of male patients in TFA access group was 35 $(70 \%)$, while, the number of males in TRA group was 37 $(74 \%)$.

Conclusion: Our study concluded that the fluoroscopy time and contrast amount were of lower levels in the TRA access than TFA access.

Key Words: CABG patients - Radial versus femoral coronary angiography.

\section{Introduction}

CORONARY angiography via TRA approach (TRA) has gained growing acceptance and operator preference in recent years, based on a reduction in vascular complications and mortality [1] when compared with TFA approach (TFA) [2].

However, it has been suggested that these advantages come at the cost of increased procedure time and fluoroscopy dose [3].

Correspondence to: Dr. Mohamed Makram E-Mail: makram m@hotmail.com
Considering the significant morbidity and mortality benefits, increased patient preference and cost effectiveness, the European Society of Cardiology now advocates the TRA as the default access route for coronary angiography [4]. Since the introduction of the TRA access for cardiac catheterization and percutaneous coronary intervention (PCI), several studies have demonstrated that such access is associated with lower rates of vascular and bleeding complications [5,6]. Although coronary artery bypass grafting $(\mathrm{CABG})$ patients comprise a significant portion of the coronary artery disease (CAD) population, this subpopulation was often excluded or under represented in TRA access studies [6,7]

A few observational studies have suggested that TRA PCI in patients who had previously undergone CABG surgery is feasible and safe, although it may require more sophisticated techniques compared to TFA PCI [8].

The RADIAL-CABG trial suggested that in patients with a history of CABG, TRA diagnostic coronary angiography was associated with greater amounts of contrast used, longer procedure time, increased number of access crossover, and higher radiation exposure of operators when compared to TFA angiography [9].

Some parts of the world, including the United States, have been slower to adopt this practice. In 2009 , less than $5 \%$ of coronary procedures were performed via TRA, however this figure has increased substantially in recent years, with estimates that around $20 \%$ of procedures are now performed radially [10] .

\section{Patients and Methods}

Study design and patient population:

Our study was a single center, retrospective cohort study was done on 100 patients to compare 
procedural variables of TRA versus TFA catheterization in patients who had previously undergone CABG surgery. In the period between February 2019 and February 2020, 100 patients who had previously undergone CABG surgery and had received diagnostic cardiac catheterizations at our institute were included in the study population.

Patients with acute coronary syndrome, chronic liver or kidney disease were excluded from our study.

The study was approved by the Cardiology institutional review board.

\section{Procedure description:}

TFA catheterization was performed via the right or left common femoral artery while TRA catheterization was performed via the left radial artery.

Intra-arterial heparin and nitroglycerin were administered via radial sheath to prevent arterial spasm and thrombosis in TRA cases. At the end of each TRA procedure, a TRA band was applied to achieve patent hemostasis.

\section{Endpoints:}

The primary study endpoint was the volume of contrast used during diagnostic coronary angiography. Secondary end points include fluoroscopy time and procedure time until the end of the diagnostic procedure (defined as the interval between administration of local anesthesia for obtaining vascular access and removal of the last diagnostic catheter). Endpoints were assessed for the whole study sample regardless of the indication for catheterization.

\section{Data collection:}

Demographics and clinical characteristics of patients along with the various endpoints of the study were retrospectively collected from thepatient's electronic records.

\section{Statistical analysis:}

Categorical variables were presented as percentages and compared using the chi-square as appropriate. Continuous variables were presented as mean \pm standard deviation (SD). The volume of contrast used during the procedure (primary endpoint), fluoroscopy time and total procedure time are continuous variablesand they were assessed by the Mann-Whitney U test. Analysis wasdone using SPSS version 24.0 statistical software. Statistically significant differences were assumed with a $p$-value $<0.05$.

\section{Results}

Our results observed in Table (1) cleared that, the number of male patients in TFA access group was $35(70 \%)$, while, the number of males in TRA group was $37(74 \%)$.

The mean age of patients in TFA group was 68.25 year, while, in TRA group was 66.69 year.

The number of grafts in TFA access was 3.95, while, in TRA group it was 3.90.

The number of hypertensive patients in the TFA group was $29(58 \%)$ while hypertensive patients were $26(52 \%)$ in the TRA group.

The number of diabetic patients was $25(50 \%)$ in the TFA group while they were 27 (54\%) patients in the TRA group.

The number of patients with dyslipidemia was $37(74 \%)$ in the TFA group while they were 36 $(72 \%)$ in the TRA group.

Smokers were $31(62 \%)$ in the tansfemoral group and 35 (70\%) in the TRA group.

Table (1): Demographic characters of the patients.

\begin{tabular}{llll}
\hline Characteristics & $\begin{array}{c}\text { TFA access } \\
(\mathrm{n}=50)\end{array}$ & $\begin{array}{c}\text { TRA access } \\
(\mathrm{n}=50)\end{array}$ & $\begin{array}{c}p \text { - } \\
\text { value }\end{array}$ \\
\hline Sex: & & & \\
$\quad$ Male & $35(70 \%)$ & $37(74 \%)$ & 0.152 \\
Age & $68.25 \pm 10.29$ & $66.69 \pm 10.05$ & 0.024 \\
Number of grafts & $3.95 \pm 1.02$ & $3.90 \pm 1.20$ & 0.24 \\
Hypertension & $45(90 \%)$ & $46(92 \%)$ & 0.45 \\
Diabetes & $25(50 \%)$ & $27(54 \%)$ & 0.024 \\
Dyslipidemia & $37(74 \%)$ & $36(72 \%)$ & 0.322 \\
Smokers & $31(62 \%)$ & $35(70 \%)$ & 0.452 \\
\hline
\end{tabular}

Values are mean $\pm \mathrm{SD}$ or $\mathrm{n}(\%)$.

Procedural outcomes are depicted in Table (2). Compared with TRA approach, patients undergoing coronary angiography via TFA access had a more contrast use (69.3ml vs. 42.81) and longer fluoroscopy time (7.20min vs. $4.90 \mathrm{~min}$ ), and there were no major peri-procedural complications.

Table (2): Procedural outcomes.

\begin{tabular}{lccc}
\hline Characteristics & $\begin{array}{c}\text { TFA access } \\
(\mathrm{n}=50)\end{array}$ & $\begin{array}{c}\text { TRA access } \\
(\mathrm{n}=50)\end{array}$ & $\begin{array}{c}p \text { - } \\
\text { value }\end{array}$ \\
\hline Contrast volume, $\mathrm{ml}$ & $69.3 \pm 13.2$ & $42.8 \pm 10.2$ & 0.0012 \\
Fluoroscopy time, min & $7.20 \pm 3.11$ & $4.90 \pm 2.24$ & $<0.001$ \\
Procedure time, $\min$ & $17.25 \pm 5.24$ & $15.35 \pm 6.22$ & $<0.32$ \\
\hline
\end{tabular}

Values are mean $\pm \mathrm{SD}$ or $\mathrm{n}(\%)$. 


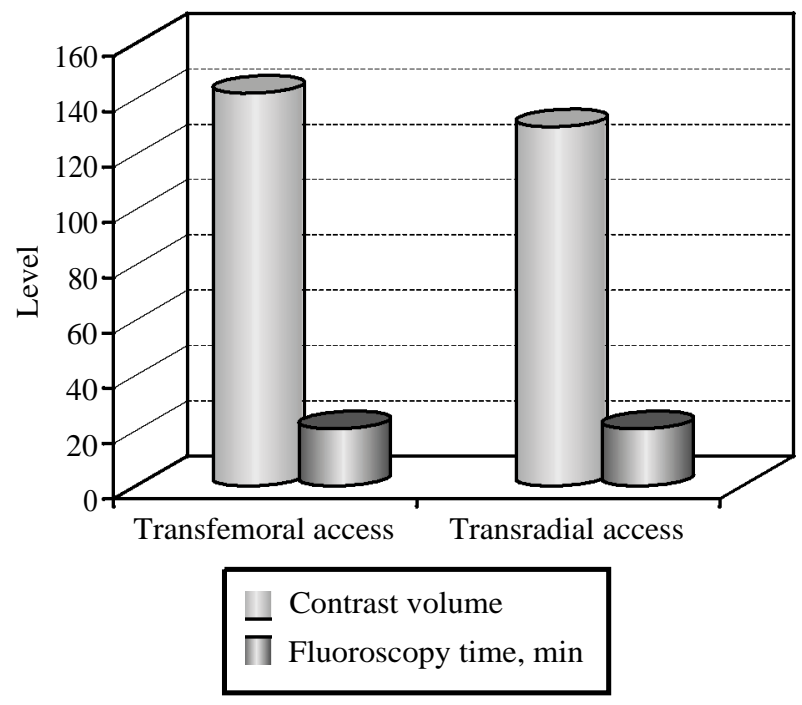

Fig. (1): Fluoroscopy time and contrast volume in TFA and TRA access.

\section{Discussion}

This retrospective analysis shows that angiography of post-CABG patients can be safely performed via left TRA with significant lowering of both contrast amount and fluoroscopy time and without significant increase in peri-procedural complications.

There is no significant difference regarding the whole procedure time between TFA and TRA coronary angiography.

Although it may also be technically extra challenging, left TRACAG has emerged as a promising method with many feasible blessings over TFAapproach especially in patients with previous history of CABG, with easier visualization of LIMA graft

It is important to reduce procedural time to achieve more patients comfort and more cost effectiveness, previous studies have already shown that TRA is more cost effective than TFA due to earlier ambulation and time to discharge [6] .

Moreover, fluoroscopy time remains and important factor regarding the operator's safety due to its direct proportion with increased malignancy

Despite Michael et al., concluded in a prospective randomized trial comparing TFA and TRA in patients post $\mathrm{CABG}$ undergoing diagnostic angiography and/or PCI that TRA resulted in longer procedure times, without statistically significant increase in patient radiation exposure [9]. However, this significant difference decreased in patients who underwent PCI, only male patients included in that study, with significant crossover rate from radial to femoral route of $17 \%$. This high crossover rate may have been partly attributable to lack of experience of first operators and their underlying inexperience in TRA, and this lack of experience might have been a major contributor to the longer procedural time.

\section{Conclusion:}

Our study concluded that coronary angiography of post-CABG patients can be safely performed via left TRA with significant lowering of both contrast amount and fluoroscopy time and without significant increase in peri-procedural complications.

\section{References}

1- AGOSTONI P., et al.: Radial versus femoral approach for percutaneous coronary diagnostic and interventional procedures; Systematic overview and meta-analysis of randomized trials. J. Am. Coll. Cardiol., 44 (2): p. 34956, 2004.

2- HIRZALLAH H., et al.: Comparison of Transradial and Transfemoral Approaches for Coronary Angiography and Percutaneous Intervention in Patients with Coronary Bypass Grafts. Cardiovasc. Revasc. Med., 21 (1): p. 25, 2020.

3- JOLLY S.S., et al.: Radial versus femoral access for coronary angiography and intervention in patients with acute coronary syndromes (RIVAL): A randomised, parallel group, multicentre trial. Lancet, 377 (9775): p. 140920, 2011.

4- RATHORE S., et al.: The feasibility of percutaneous transradial coronary intervention for saphenous vein graft lesions and comparison with transfemoral route. J. Interv. Cardiol., 22 (4): p. 336-40, 2009.

5- RAO S.V., et al.: Trends in the prevalence and outcomes of radial and femoral approaches to percutaneous coronary intervention: A report from the National Cardiovascular Data Registry. JACC Cardiovasc. Interv., 1 (4): p. 37986, 2008.

7- PASLEY T.F., et al.: Left Radial Versus Femoral Access for Coronary Angiography in Post-Coronary Artery Bypass Graft Surgery Patients. J. Invasive Cardiol., 28 (3): p. 814, 2016.

8- ROMAGNOLI E., et al.: Radial versus femoral randomized investigation in ST-segment elevation acute coronary syndrome: The RIFLE-STEACS (Radial Versus Femoral Randomized Investigation in ST-Elevation Acute Coronary Syndrome) study. J. Am. Coll. Cardiol., 60 (24): p. 24819, 2012.

9- BUNDHOO S.S., et al.: Saphenous vein graft percutaneous coronary intervention via radial artery access: Safe and effective with reduced hospital length of stay. Am. Heart J., 164 (4): p. 468-72, 2012.

10- FRANGOS C. and NOBEL S.: How to transform you into a radialist: Literature review. Cardiovasc. Med., 14: 277 282,2011 
11- MICHAEL T.T., et al.: A randomized comparison of the transradial and transfemoral approaches for coronary artery bypass graft angiography and intervention: The RADIAL-CABG Trial (RADIAL Versus Femoral Access for Coronary Artery Bypass Graft Angiography and Intervention). JACC Cardiovasc. Interv., 6 (11): p. 1138-44, 2013.
12- PAPPY R., et al.: Effect of statin therapy on contrastinduced nephropathy after coronary angiography: A metaanalysis. Int. J. Cardiol., 151 (3): p. 348-53, 2011.

13- ANDREASSI M.G., et al.: Acute chromosomal DNA damage in human lymphocytes after radiation exposure in invasive cardiovascular procedures. Eur. Heart J., 28 (18): p. 2195-9, 2007.

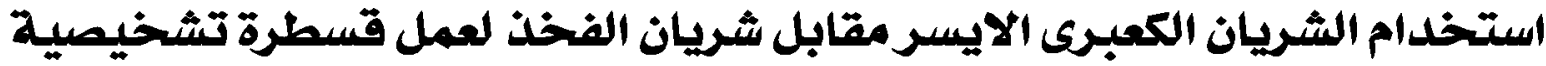

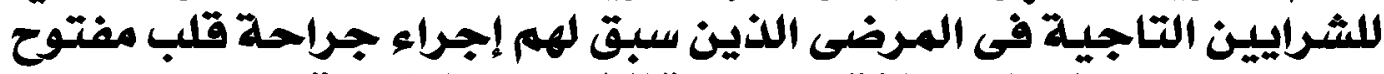

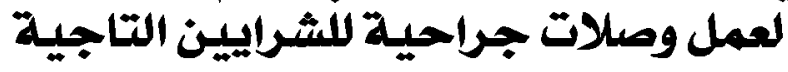

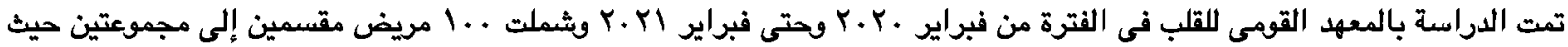

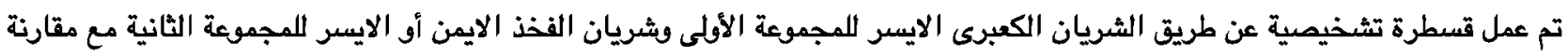 \\ كمية الصبغة المستخدمة وققت التعرض للاشعة فى المجموعتين. \\ وأظهرث النتائج انخفاض كمية الصبفة المستخدمة فى المجموعة التى استخدم فيها الشريان الكعبرى الايسر مع انخفاض وقت التعرض \\ للاشعة بنفس المجموعة مقارنة بالمجموعة الاخرى مع علم حدوث مضاعفات مؤثرة.

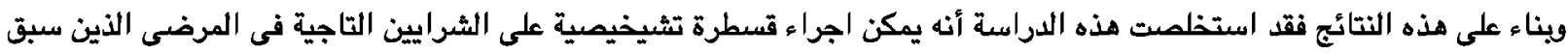

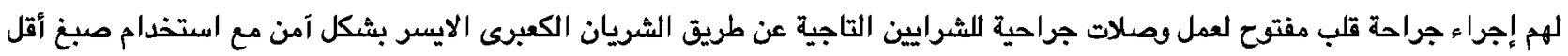 \\ والتعرض للاشعة بشكل أقل مقارنة بالطرق التقليدية.
}

